IAAA

\title{
AIAA 2000-3603
}

\section{A NASA SPACELINER 100 PROPULSION ORIENTED TECHNOLOGY ASSESSMENT}

W. Dankhoff, K. Dayton, D. Levack, P. Odom, R. Rhodes and J. Robinson

Space Propulsion Synergy Team

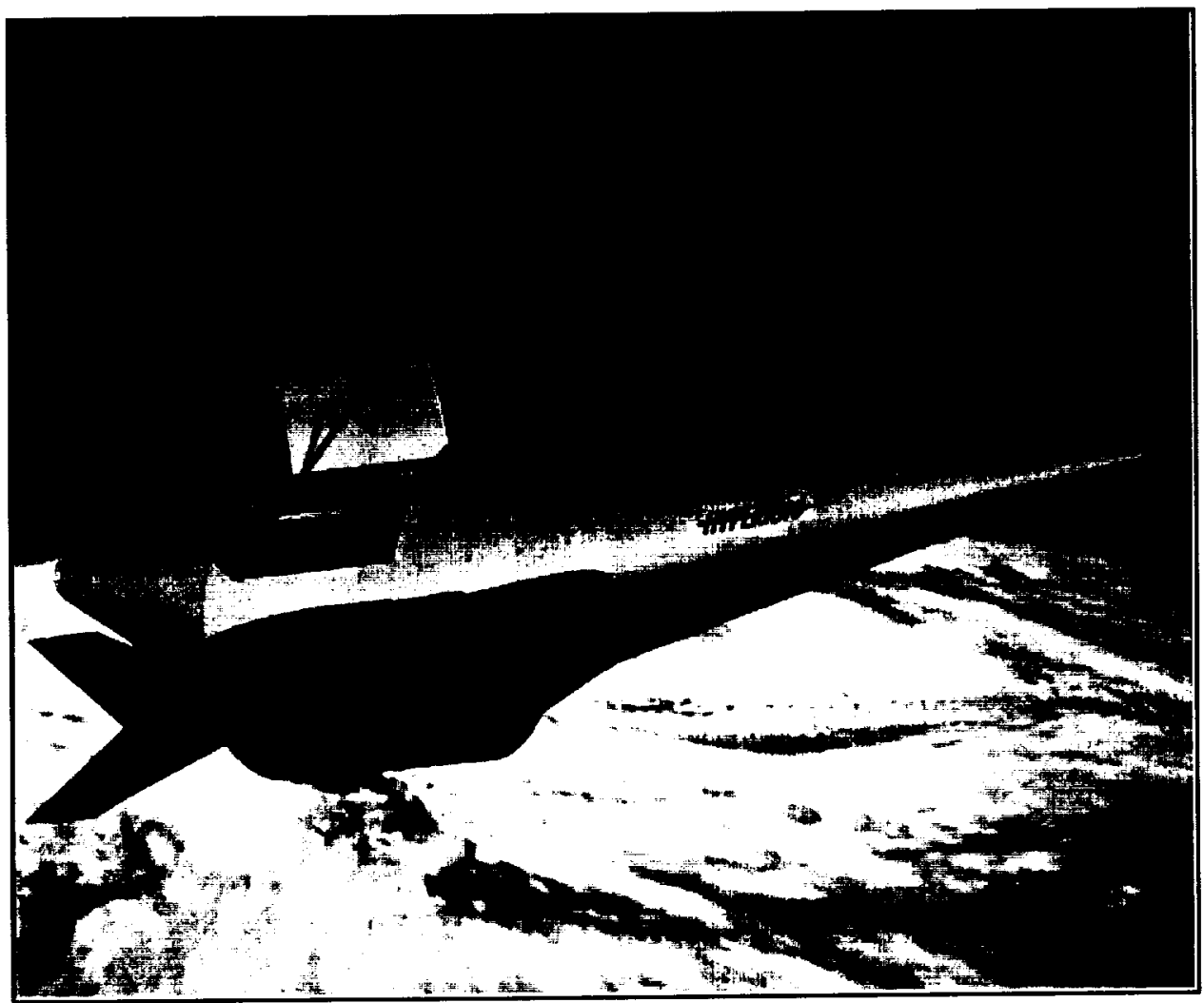

\section{$36^{\text {th }}$ AIAAASME/SAE/ASEE Joint Propulsion Conference \\ July 17-19, 2000 \\ Huntsville, Alabama}

For permission to copy or lo republish, conlact the American Institute of Aeronaulios and tstruenutics. 1801 Alexamer Bell Drive, Suite S00, Resion, VA, 20191-434t. 



\section{A NASA SPACELINER 100 PROPULSION ORIENTED TECHNOLOGY ASSESMENT}

By

\section{THE SPACE PROPULSION SYNERGY TEAM}

\begin{abstract}
In response to a NASA request, the National Space Propulsion Synergy Team (SPST) team agreed to provide technical and programmatic support to NASA in formulating a Spaceliner 100 Technology Program. The SPST offered a broad cross-section of expertise and experience. Its membership consists of senior level, volunteer representatives from across government, industry, and academia.
\end{abstract}

The purpose of this paper is to provide a summary of the SPST support of $S L 100$, which culminated in a propulsion technologies assessment and prioritization workshop conducted at MSFC. The results of this workshop and the follow-up analysis are part of this report. Also included, is a review of some "lessons learned" that were solicited from the workshop participants.

\section{SPST Organization And Operations}

The mode of operation of the SPST in responding to a request from a customer is shown in Figure 1.

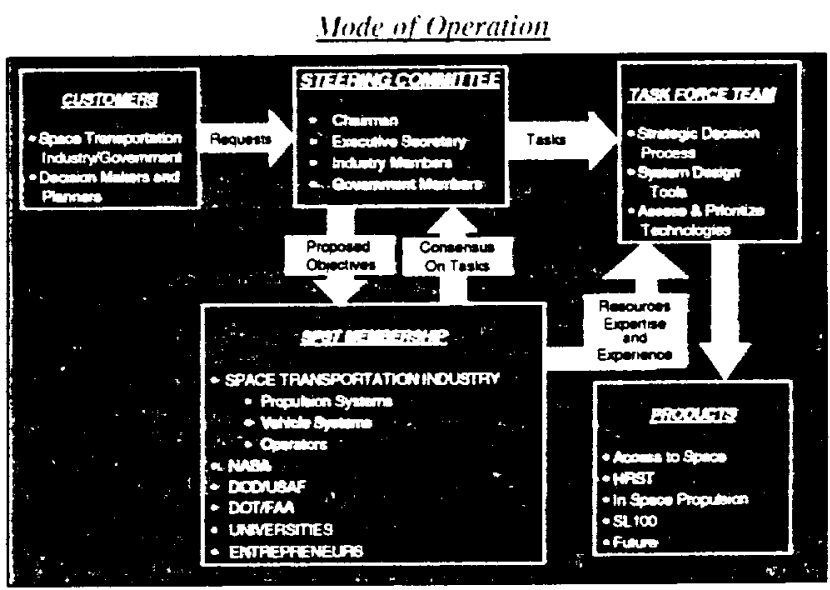

FIGURE 1

In response to a customer's request the SPST Steering Committee, with consensus from the membership, defines the task and organizes the voluntary manpower that will be required. Consistent with this mode of operation, a diversified, experienced task force was formed to carry out the support of the SL100 technology program planning. Four subteams were formed to conduct this effort:

Team 1- Functional Requirements

Team 2 - Space Transportation Architectures

Team 3 - Technologies Identification and Characterization

Team 4 - Technologies Prioritization 
The overall management and coordination of the support task force was assigned to Walt Dankhoff, the Executive Secretary of the SPST. During the first half of the life of the SL100 Technologies Support Task Force the Chemical Propulsion Information Agency (CPIA) was responsible for providing administrative services for the SPST, including the technical and administrative service of the Executive Secretary. However, beginning February 1, 2000 the administrative services, including that of the Executive Secretary, were provided by Science Applications International Corporation (SAIC) as one part of an existing contract with MSFC.

The Task Force consisted of the four teams named above. Each team had a balanced membership of representatives from across Government (NASA and USAF), Industry and Academia. The responsibilities and functions of each of these teams are addressed in the following section, which presents an overview of the SPST support of SL 100.

\section{Overview Of SPST Support Of} SL 100 Technologies

Although the SPST team support was focused on propulsion systems, the approach was to consider propulsion systems in the broadest sense, i.e. from propellant supply systems to exhaust nozzles and not just the engine. The ground infrastructure and operations, which are largely driven by the type of propulsion system and propellants, was highlighted in the scope of support.

The basic task of the SPST was to identify, define, and prioritize the propulsion systems technologies that are critical to enabling the development and operation of a space transportation service capable of meeting the challenging goals that are embedded in RLV/Gen 3. However, it was necessary for the SPST Task Force to first broadly address this task at a transportation system level as explained in the following section.

The work flow plan used in carrying out the task of SPST Support of SL100 Technologies Planning is depicted in Figure 2.

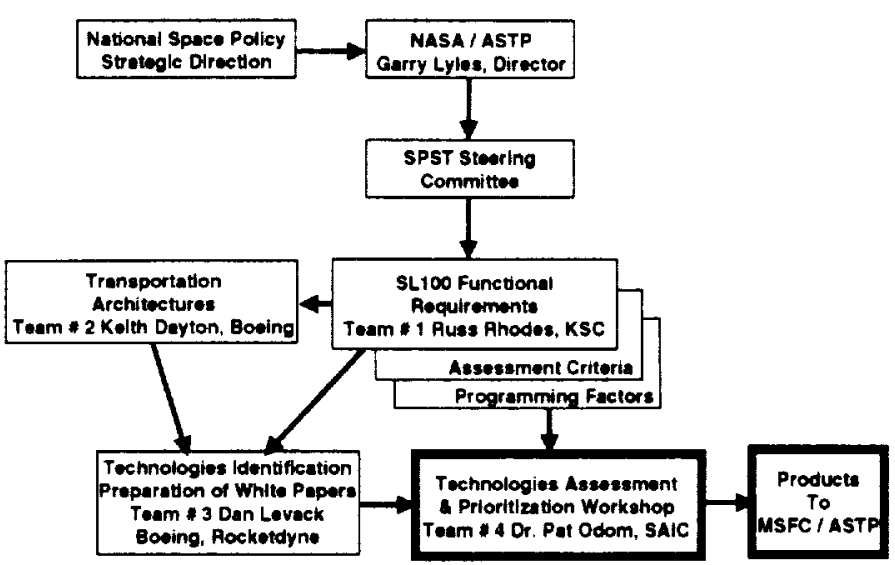

FIGURE 2

The basic requirements, or major goals, of an RLV/Gen 3 transportation service were provided by NASA/MSFC Advanced Space Transportation Program Office. They were (1) a transportation service 10,000 times safer and (2) 100 times lower costs than the current space shuttle system. 
The Functional Requirements Team 1 expanded, and further defined, the basic functional requirements of an RLV/Gen 2 transportation Service. Additionally, they defined other major attributes, including responsiveness, dependability, and environmental compatibility as functional requirements. This team provided another vital input to the Assessment and Prioritization Workshop. They identified and weighted the measurable technical design criteria and programmatic assessment factors. Fortunately, the previous SPST activities, using the same process, provided sound building blocks for the development of the criteria to assess the candidate SL100 technologies. It should be noted that in this phase of the SPST support the focus was on propulsion systems for earth to LEO transportation vehicles, sometimes referred to as "space trucks".

In parallel, Team 2 was identifying the transportation system "architectures" that were considered to have the potential of meeting these requirements. The output of both teams were utilized in identifying and defining the candidate propulsion system technologies.

The primary objective of the Technologies Team 3 was to identify and define propulsion and "propulsion related" technologies that could be candidates for inclusion in the SL100 technology budget for FY 2001 and beyond. Once this team had identified and categorized the candidate technologies they were responsible for the development of a white paper on each. In some cases a team member was asked to prepare the white paper.
However, in many cases, it was necessary to seek a commitment from an engineer outside the team to prepare the white paper.

The last step in the work flow process was the actual assessment and prioritization. This was conducted in a hands-on workshop on April 5th - 7th at MSFC. Dr. Pat Odom of SAIC, the team leader, was responsible for the planning and facilitation of this highly successful workshop. A major part of the preparation for a workshop was the selection and organization of two teams of evaluators, one technical, the other programmatic.

The process utilized in this workshop, as well as in previous workshops, was a successful marriage of two processes. The first being the QFD based process evolved and utilized by the SPST, which is addressed in References 1,2 and 3; the second process in this marriage is the AHP (Analytic Hierarchy Process), broadly used and improved by SAIC. The combination of these processes produced a credible assessment and prioritization of the candidate technologies. The results of the workshop have been provided to the NASA ASTP. In addition, specific analyses of the data, such as sensitivity analysis, are being carried out, as requested by the NASA.

The reader should note that the results and conclusions presented herein do not represent official NASA positions on the priorities of particular space propulsion technologies. Rather, they are the "output" of the collaborative process utilized by the SPST in the SL100 Technologies Workshop. The 
results of the workshop are, therefore, an input to NASAMSFC for utilization in their FY 2001 budget planning process.

It should be emphasized that an additional, extremely valuable product of the subject task was the maturing of the SPST/AHP process that took place. Each time this process is exercised there are "lessons learned" that, when applied, result in a more efficient and credible process, including the workshops. For example, if this process is utilized to support the development of a cost effective technology plan for the $\mathrm{RLV} / \mathrm{Gen} 2$, it will require fewer man hours and a somewhat shortened time span.

\section{Functional}

\section{Requirements (Team 1)}

The primary purpose of the Function Requirements Team was to define and prioritize the functional requirements of a space transportation system that has the potential of meeting the challenging goals NASA defined for an RLV/Gen 3 system. In other words, defining the needs of the transportation service customer. This team was also responsible for defining and prioritizing the "hows" i.e. how can a transportation system provide "what" the customer wants. The "hows" were defined in terms of measurable criteria (technical/design and programmatic) these criteria became inputs to the workshop and were utilized in the assessment and prioritization of the candidate technologies for an RLV Gen 3 transportation system that would support/correlate with the desired attributes. These are discussed next. This team started with NASA's strategic directions for a RLV/Gen3 as outlined as follows.

- Assuring reliable and affordable access to space through U.S. transportation capabilities is fundamental to achieving national space goals.

- Must improve reliability, operability and responsiveness to be in concert with achieving the Safety and Cost goals for 3drd Generation Space Transportation.

- Safety: Aircraft-Levels of Flight Safety Paramount.

- Cost: $\$ 100$ per pound to Orbit equivalent.

- Service: Capable of supporting all Earth Orbit transportation requirements, including all orbits from LEO to GEO.

- Customers: Must support Space Transportation needs of Commercial, Civil, DOD, and National Security.

Further inputs from NASAMSFC were used in deriving the specific functional requirements shown in Table 1 . They have been categorized by first the transportation service capability and then the major attributes or characteristics that are required of an RLV/Gen 3. In expanding upon these basic functional requirements this team relied heavily on the outputs from previous SPST tasks. 


\section{TABLE 1 \\ Summary of Functional Requirements Summary For RLV/GEN 3 (SPACELINER 100)}

\section{TRANSPORTATION SERVICE CAPABILITY}

- Earth Orbit Capabilities:

LEO 40.000 pounds @ 28.6

- Cross-Range

Degrees-100 NM

See Reference \#3

SAFETY

- Paramount

- Loss of vehicle: $\quad 1 / 10,000$ or 0.9999 Rel.

- Loss of crew or passengers: 1 in 1,000,000 flights

- Cross-range: See Reference \#3

- Public Safety: 30 in $1,000,000$ flights

AFFORDABILITY

- Cost: $\quad \$ 100$ per pound to Orbit

- Integration of systems with like functions: See Reference \#3

- \# of interfaces, and independent sub-system: See Reference \#3

RESPONSIVENESS

- Ground turnaround time: 1 day maximum

- Operations/Environment Maintainability:

Automated health management

Ready accessibility

Min. use of pollutive or toxics

- Range Control:

Automated system

- Fleet Service Capability:

1,000 flights per year

200 flights per vehicle per

year

DEPENDABILITY

- Reliability /Safety: See Reference \#3

- Dynamic propulsive events/operating modes: See Reference \#3

- Critical failure modes and fault tolerant: See Reference \#3

- Use of closed compartments and active safing: See Reference \#3

- Vehicle Life:

10,000 flights per vehicle

- Depot Maintenance:

Every 1,000 flights

ENVIRONMENTAL

See Reference \#3 
The previously identified customer desired attributes, that is, what the customer desires in a space transportation system (see Figure 3) were found to be directly applicable with a few additions. It should be noted that there are two categories of Assessment Criteria.

Those in the upper part of Figure 3 are the attributes that are desired in an operating space transportation system, and reflect recurring costs. The attributes in the lower portion of this chart are those desired in the R\&D and acquisition phase of a space transportation system. This phase is characterized as non-recurring costs, and is referred to in the SPST process as programmatic.

Next this team, using a collaborative QFD type process, prioritized (weighted) the space transportation attributes. First, this team evaluated the current operating space transportation systems (i.e., Space Shuttle and expendable launch vehicles) relative to these attributes. This was accomplished using a scoring of 1 to 5 . The higher number indicates a greater ability of the transportation system to meet the attribute requirements.

A critical next step was for the team, again in a collaborative process, to determine the level of improvement required in each attribute. However, before proceeding it was necessary to have the customer, in this case ASTP, provide a weighting of the attributes.
Acting in the role of the customer, Uwe Hueter, provided the required assessment. The final score (weighting), was determined by adding the customer's ranking of importance of the attribute plus the "need to improve" number (ratio).

It is beyond the scope of this paper to present the details of the development and prioritization of the measurable design criteria and the programmatic factors, which were employed in the Technology Prioritization Workshop. However, they may be found in References 3 and 4 . An example of the correlation (scoring) of the measurable design criteria ("hows") with two of the desired system attributes (affordable and dependable) is shown in Table 2. These prioritized design criteria along with many others, were utilized in the assessment workshop (see References 3 and 4).

\section{Space Transportation Architectures (Team 2)}

As previously noted the basic task of the SPST was to identify, define and prioritize propulsion system technologies that are critical to enabling the development and operation of a space transportation service capable of meeting the challenging goals that are embedded in NASA's Gen 3 safety and cost goals. However, it was necessary to also broadly address this task at the transportation system level. 


\section{The Attributes of a Space Transportation System}

\begin{tabular}{|c|c|}
\hline $\begin{array}{l}\text { Afrordable / Low Life Cycle Cost } \\
\text { Min. Cost Impact of Payloads on Launch Sys. } \\
\text { Low Recurring Cost } \\
\text { l.ow Cost Sensitivity to Flight Growth } \\
\text { Operation and Support } \\
\text { Initial Acquisition } \\
\text { Vehicle/System Replatement } \\
\text { Dependable } \\
\text { Highly Reliable } \\
\text { Intact Vehicle Recovery } \\
\text { Mission Success } \\
\text { Operate on Command } \\
\text { Robustness } \\
\text { Design Certainty } \\
\text { Environmental Compatibility } \\
\text { Minimum Impact on Space Environ. } \\
\text { Minimum Effet on Atmosphere } \\
\text { Minimum Impact all Sites } \\
\text { Public Support } \\
\text { Benefit GNP } \\
\text { Social Perceplion }\end{array}$ & $\begin{array}{l}\text { Responsive } \\
\text { Flexible } \\
\text { Capacity } \\
\text { Operable } \\
\text { Process Verification } \\
\text { Auto. Sys. Health Verification } \\
\text { Auto. Sys, Corrective Action } \\
\text { Easc of Vehicle/System } \\
\text { Integration } \\
\text { Maintainable } \\
\text { Simple } \\
\text { launch on Demand } \\
\text { Easily Supportable } \\
\text { Resiliency } \\
\text { Safety } \\
\text { Vehicle Salety } \\
\text { Personnel Safety } \\
\text { Public Satiety } \\
\text { Equipment and Facility Salety }\end{array}$ \\
\hline Durung the Technology R\&D Phase: & During the Program Acquisition Phase: \\
\hline $\begin{array}{l}\text { Affondable / Low Life Cycle Cost } \\
\quad \text { Cost to Develop } \\
\text { Benefit Focused } \\
\text { Schedule } \\
\text { Risk } \\
\text { Dual Use Potential }\end{array}$ & $\begin{array}{l}\text { Affordable / Low Life Cycle Cost } \\
\quad \text { Cost to Acquire } \\
\text { Schedule } \\
\text { Risk } \\
\text { Technology Options } \\
\text { Investor Incentive }\end{array}$ \\
\hline
\end{tabular}
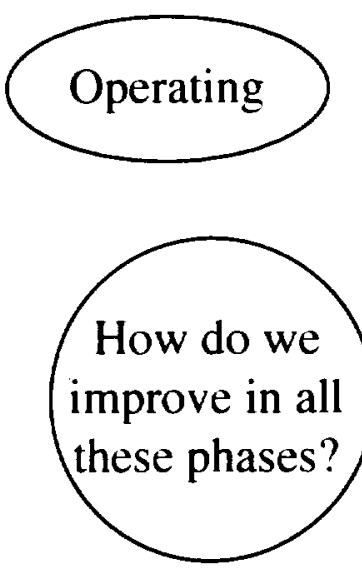

FIGURE 3

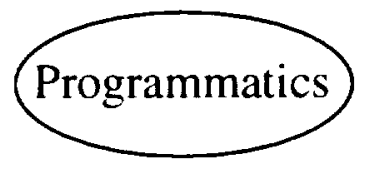




\section{Example of Correlation (Weighting) of Design Criteria with the Attributes "Affordable and Dependable"}

\author{
Affordable/Low Life Cycle Cost \\ Min. Cost Impact on Launch Sys. \\ Low Recurring Cost \\ Low Cost Sens. To Fit. Growth \\ Operation and Support \\ Initial Acquisition \\ Vehicle/System Replacement
}

of unique stages (flight and ground) $(-)$

of active on-board space sys. req'd for propulsion (-)

On-board Propellant Storage \& Management Difficulty in Space (

Technology readiness levels $(+)$

Mass Fraction required $(-)$

Ave. ISP on refer. Trajectory (+)

of umbs. Req'd to Launch Vehicle $(-)$

of engines $(-)$

Resistance to Space Environment (+)

Integral structure with propulsion sys. (+)

Transportation trip time (-)

\section{Dependable}

Highly Reliable

Intact Vehicle Recovery

Mission Success

Operate on Command

Robustness

Design Certainty

No. 10 \# of active components required to function including flight

$$
\text { Operations (-) }
$$

Design Variability $(-)$

of different fluids in system (-)

of active engine systems required to function (-)

of modes of cycles $(-)$

Margin, mass fraction $(+)$

Margin, thrust leveVengine chamber press (+)

of engine restarts required (-)

$\begin{array}{ll}\text { Raw } & \% \\ \text { Score } & \text { Weight } \\ 483 & 5.3 \% \\ 454 & 4.9 \% \\ 453 & 4.9 \% \\ 425 & 4.6 \% \\ 387 & 4.2 \% \\ 310 & 3.4 \% \\ 276 & 3.0 \% \\ 274 & 3.0 \% \\ 268 & 2.9 \% \\ 239 & 2.6 \% \\ 211 & 2.3 \%\end{array}$

$\begin{array}{ll}\text { Raw } & \% \\ \text { Score } & \text { Weight }\end{array}$

$527 \quad 5.7 \%$

$464 \quad 5.0 \%$

$404 \quad 4.4 \%$

$247 \quad 2.7 \%$

$227 \quad 2.5 \%$

$215 \quad 2.3 \%$

$211 \quad 2.3 \%$

$201 \quad 2.2 \%$ 
Therefore, a transportation system Architectures Team was formed to: (1) identify and define space transportation system architectures that have the potential of satisfying the RLV/Gen 3 functional requirements, and (2) identify and define the major system elements within these architectural concepts. The overall purpose was to provide a means of identifying key propulsion related technologies to enabling the development of an RLV/Gen 3 system that might otherwise be overlooked.

To accomplish these objectives, the Architectures Team was staffed with senior level Industry, Government (NASAUUSAF), and Academia volunteers who represented a broad cross-section of technical breath and expertise.

The basic approach emphasized by this team was as follows:

1. To identify and conceptually define space transportation system architectures which have the potential of addressing the functional requirements that were defined by Team No. 1.

2. To identify and define the major elements that constitute these space transportation architectures.

In view of the advanced and challenging nature of the RLV/Gen 3 transportation system requirements; and the limited availability of previous related system analysis and engineering studies, the approach of this team had to be:
- At a top system level in terms of mission capabilities

- Very conceptual level of design penetration

The elements within the transportation system architectures include several types of space transportation vehicles, as well as the required ground operational support infrastructure. The potential transportation service architectural concepts and payloads beyond LEO were included because they may have requirements that will impact the design of the earth to LEO vehicles.

Also recognizing that the objective of this task was to identify and prioritize propulsion and propulsion-related technologies, the focus of this team was on the roles that propulsion played in defining the various space transportation system vehicles. Therefore, for this specific activity the focus was on propulsion systems for earth to LEO transportation vehicles i.e., space trucks.

Using the results of previous studies, systems applicable to the Gen3 RLVs were identified in terms of the overall vehicle concept configuration, staging, takeoff/landing approach, launch assist, number of propulsion stages, and propellants for both "earth to orbit" and "orbit to orbit" concepts. Generic concepts of transportation architecture, system elements were identified then grouped by categories. 
These generic system concepts were evaluated against the attributes/functional requirements that were previously developed. The weighting was based on the generic system concept's contribution to, or correlation with, each of the attributes/functional requirements.

It was noted that the consensus of this structured evaluation was that all of these generic system concepts were primary contributions to the achievement of the functional requirement of an RLV/Gen 3. There were only a few scores for secondary contribution, notably those related to the major attribute "Dependability", and to the specific functional requirement "Dynamic Propulsion Events Operating Modes".

The key message here is that investment in the technologies associated with these concepts would benefit most of the functional requirements associated with an RLV/Gen 3 transportation system. However, this does not mean that one can conclude that any of these generic system concepts will result in a space transportation system that meets the goals of RLV/Gen 3. But, it is encouraging to note that these system concepts are considered to have the potential of being primary contributors to essential all of the attributes/functional requirements. This is an encouraging observation; for there is a general consensus that all of the system attributes must be embedded in a space transportation system, if it is to attain the safety and cost goals.
To summarize, the Architecture Team studies identified candidate vehicle concepts for the Gen3 Reusable Launch Vehicles in the time frame 2025-2030. The following categories of vehicle features were identified.

1. Propulsion elements included chemical rocket engines, pulsed detonation rocket engines, rocketbased combined-cycle and turbine based-combined cycle engine systems.

2. Single and two stage to orbit ETO trucks employing vertical or horizontal takeoff, horizontal or vertical landing, LOX/H2 and/or LOX/Hydrocarbon propellants; and launch assist (e.g., MagLev) or no launch assist.

3. There were no exotic propulsion systems evaluated in this study (i.e., propellant-less, beamed energy, etc) at the request of NASA's ASTP Office.

These results were utilized as a frame of reference in the identification and assessment of the candidate technologies for SL 100.

\section{Technologies Identification \& Characterization (Team 3)}

The primary objective of the Technology Team was to identify and define propulsion and propulsionrelated technologies that are candidates for inclusion in the SL100 technology budget for FY 2001 and beyond. This team chose to use three available sources in identifying the candidate technologies. First the 
technologies identified by NASA during the summer of 1999, as candidates for an advanced space transportation system, were assimilated. From these were abstracted those that were propulsion or propulsion related. This process reduced the list of technologies from 48 to 21 . Interactions with Team 2 (Architectures) and discussions within Team 3 led to the inclusion of two additional technologies - Thrust Augmentation and Bridge to Space (Tether second stage). The net result was that 23 technologies were presented at the AHP workshop. They were grouped into three categories: Enabling/Generic Technologies, Flight Systems, and Ground Systems, which are defined as follows.

\section{- Enabling/Generic Technologies}

As the title implies this category of technologies has the potential of applying to several "flight systems" or in some cases "ground systems". A good example of a technology that fits in this category is propulsion Integrated Vehicle Health Management (IVHM).

\section{$>$ Flight Systems}

The Flight System Technologies are basically propulsion systems that are candidates for a number of space transportation vehicles. Each type of propulsion system is treated as a complete technology in itself. However, it is obvious that there are many lower level technologies associated with subsystems, components, etc.

\section{Ground Systems}

This category of technologies was specifically established recognition of the fact that efficient ground operations are paramount to attaining the challenging goals of an RLV/Gen 3 transportation service. Each of the technologies included in this category contributes to ground operation efficiency. However, it is recognized that many other technological advancements related to all aspects of ground operations are needed to meet the RLV/Gen 3 goals.

This team was not only responsible for identifying and assimilating candidate technologies, as shown in Table 3, but they were also responsible for the preparation of a white paper on each of the candidate technologies.

In order to have consistency in the format and content of these technology white papers each author was provided with a template to use as a guide. The template defined and required the following items:

- Technology Category

- Summary Description

- Spaceliner Architecture/System/ Subsystem Application(s)

- Investments Required to Mature the Technology for Spaceliner Potential Benefits of the Technology to Spaceliner

In addition, the authors were provided with the major products of the Functional Requirements (Team 1). These included the prioritized criteria (technical/design and programmatic factors) that would be used in the Technology Assessment and Prioritization Workshop. 
TABLE 3

\section{PREPARATION \& BRIEFING OF TECHNOLOGY "WHITE PAPERS"}

\section{Enabling/Generic Technologies:}

- Aerodynamic performance and control through drag modulation (Ray Chase/ANSER)

- High performance hydrocarbon fuels (Joe Ciminski) - by telecon

- Thrust augmentation (Mike Blair/Thiokol)

- Propulsion IVHM (June Zakrajsek/GRC) - by telecon

- Numerical propulsion system simulations (NPSS) for space transportation propulsion (Karl Owen/GRC) - by telecon

- High (better than densified density hydrogen) (Bryan Palaszewski /GRC) - by telecon

- Advanced cryotank structures (Earl Pansano/Lockheed Martin)

- Long life, light weight propulsion materials and structures (Dan Levack/Boeing-Rocketdyne)

- Bridge to space (tether second stage) (Tom Mottinger/Lockheed Martin) - by telecon

- Green, operable RCS (Eric Hurlbert/JSC and Stacy Christofferson/Primex) by telecon

Two different concepts

Flight Systems:

- Baseline/Pivot Technology for Main Propulsion and OMS/RCS (Dan Levack/BoeingRocketdyne and Stacy Christofferson/Primex)

- Long life, high TW hydrogen rocket (Dan Levack/Boeing-Rocketdyne)

- Long life, high TW hydrocarbon rocket (Uwe Hueter/MSFC)

- Hydrocarbon TSTO RBCC (Dick Johnson/Aerojet) - by telecon

- SSTO hydrogen RBCC (Dick Johnson/Aerojet) - by telecon

- TSTO hydrogen airbreather (Bill Escher/SAIC)

- SSTO TBCC airbreather (Bill Escher/SAIC)

- Pulsed detonation engine rocket (Dan Levack/Boeing-Rocketdyne)

- Airbreathing pulsed detonation engine combined cycle (Dan Levack/Boeing-Rocketdyne)

Ground Systems:

- Baseline/Pivot technology for ground systems (Edgar Zapata/KSC)

- Advanced checkout and control systems (Edgar Zapata/KSC)

- Intelligent instrumentation and inspection systems (Edgar Zapata/KSC)

- Advanced umbilicals (Edgar Zapata/KSC)

- On-site, on-demand production and transfer of cryogenics (Edgar Zapatal

- KSC) 
The authors were also provided with a document (see Reference 4) that defined each assessment criteria. In this manner, the authors were made aware of the assessment criteria (prioritized) that would be utilized in the Workshop and could take this knowledge into account in preparing their white papers. These white papers were made available prior to the workshop. Each author was also required to provide an on-site briefing or telecon briefing.

In addition to the input of candidate technologies, the AHP assessment and prioritization process required the identification of a pivot technology. This pivot technology, which was also provided by this team was then used as a basis of comparison in the assessment process. The utilization of a pivot technology is described further in the assessment and prioritization section of this paper.

It is beyond the scope of this paper to describe each technology. However, for each technology presented, certain information was available on a server at MSFC and is also available as a starting point for future workshops. Up to four items were available: a quad chart from a NASA exercise in the summer of 1999, a short briefing for the workshop, a white paper, and a table of design criteria used for discrimination among technologies with comments regarding the particular technology in relation to these criteria.

\section{Assessment \& Prioritization of Technologies (Team 4)}

The Technologies Assessment and Prioritization Team of the SPST was assigned the responsibility of (1) defining the process to be used for prioritization of the identified candidate Spaceliner 100 propulsion technologies, (2) recruiting and arranging the participation of an appropriate group of expert evaluators to exercise the process, and (3) planning and facilitating the prioritization workshop culminating the technologies assessment process.

The overall technologies prioritization process used for the Spaceliner 100 Propulsion Technologies Prioritization Workshop (see Figure 4) was based directly on the Analytic Hierarchy Process (AHP) methods and techniques developed by SAIC for the Advanced Space Transportation Program beginning in the Fall of 1997. The AHP methodology (Reference 5) is based on defining a hierarchy of prioritization criteria, collaboratively weighting the criteria, and then collaboratively making pairwise comparisons of the candidate technologies against each of the evaluation criteria. The pairwise comparisons are recorded according to an established numerical scale, and may be based on either quantitative or qualitative information. The resulting collaborative input data are processed to produce a numerical prioritization of the candidate technologies. 
The AHP process has been successfully utilized in several NASA assessment and prioritization workshops. The purpose of these workshops was to assess and prioritize advanced space transportation systems technologies. The "lessons learned" from each of these activities have been routinely used to improve and mature the AHP process.

As previously described. There were two major inputs to the SL 100 technologies workshop. The first input was the prioritization technical and programmatic criteria that were identified, defined and weighted by the SPST Functional Requirements Team. Collaborative weighting of the criteria was accomplished using a Quality Function Deployment (QFD) technique. The second input was the candidate propulsion system technologies that were identified by the SPST Technologies Team and documented in white papers by the technology advocates for each technology, according to a standard white paper template. It was important to present information in each white paper to show the potential benefits of the candidate technology relative to the identified technical and programmatic evaluation criteria. The potential Spaceliner 100 system architectures identified by the SPST Space Transportation Architectures Team were used to ensure that all critical technology requirements were covered by the Technologies Team.

A team of propulsion technologies and systems experts from across NASA, $D o D$, industry, and academia was recruited to serve as evaluators in the prioritization workshop. evaluator was assigned either as a technical or as a programmatic evaluator. The evaluators were provided with the information necessary to prepare for participation in the workshop including a description of the prioritization process and electronic access to the technology white papers.

Listed alphabetically by last name, the technical evaluators were as follows:

1. Kevin Bowcutt, The Boeing Company

2. Roger Campbell, Boeing Rocketdyne Drew DeGeorge, Air Force Research Laboratory

4. Bruce Farner, Air Force Research Laboratory

5. Mike Groves, Lockheed Martin

6. Dr. Clark Hawk, University of Alabama in Huntsville

7. Merl Lausten, Aerojet

8. Tom Meredith, NASA Stennis Space Center

9. Dave McGrath, Thiokol

10. Dennis Petley, NASA Langley Research Center

11. Jay Penn, Aerospace Corporation

12. W. T. Powers, NASA Marshall Space Flight Center

13. Costante Salvador, Pratt \& Whitney

The programmatic evaluators were as follows:

1. Raymond Byrd, Boeing Aero Operations/ KSC

2. Ramon Chase, ANSER

3. Frank DeLange, Aerojet

4. David Giere, Lockheed Martin Space Systems 
5. Mark Gonda, Boeing/ Seal Beach

6. David Goracke, Boeing Rocketdyne

7. Vic Giuliano, Pratt \& Whitney

8. Lt. Col. Daniel Heale, Air Force Research Laboratory

9. Carey McCleskey, NASA Kennedy Space Center

At the workshop, the evaluators were given an update on the candidate technologies to be prioritized and a briefing to discuss the evaluation criteria and their interpretation. The candidate technologies were organized into three categories: Flight Systems, Ground Systems, and Enabling/Generic technologies. SAIC provided an orientation to the Analytic Hierarchy Process and the use of the TIPS facilitation software. The TIPS software enables a team of evaluators to collaboratively prioritize a set of candidate technologies using the Analytic Hierarchy Process (AHP).

The team of technical and programmatic evaluators was systematically facilitated through the Analytic Hierarchy Process to prioritize candidate technologies within each of the three technology categories. For each category, the pivot or reference technology was briefed (see Figure 5). Then one by one, each of the candidate technologies within that category was briefed and evaluated by the team using the TIPS software user interface to make the pairwise comparison of the given technology to the pivot technology against each technical or programmatic criterion. The technology briefings were given either in person at the workshop or remotely via teleconferencing. The evaluators asked questions and interacted with the technology advocate, and with each other, prior to entering their pairwise comparisons into the TIPS software database (see Figure 6). Following the completion of each category of candidate technologies, the evaluators were able to see both their individual and the total team prioritization results through the TIPS user interface.

\section{Results of the Technology Prioritization Workshop}

The baseline collaborative results of the Spaceliner 100 Propulsion Technologies Prioritization Workshop are illustrated in the following three charts. These charts present the present the collaborative prioritization results for the enabling/generic propulsion technologies (1) across all criteria, (2) against the technical criteria, and (3) against the programmatic criteria. The data for flight and ground systems technologies are provided in Reference 7.

Figure 7 summarizes the collaborative priorities of the enabling/generic technologies based on both technical and programmatic evaluation criteria. The baseline results are nominally based on equal weight being given to the technical evaluation criteria as a set, and to the set of programmatic evaluation criteria. The candidate technology are listed in rank order by the priority vector resulting from the Analytic Hierarchy Process. 


\section{Overall Technologies Prioritization Process}

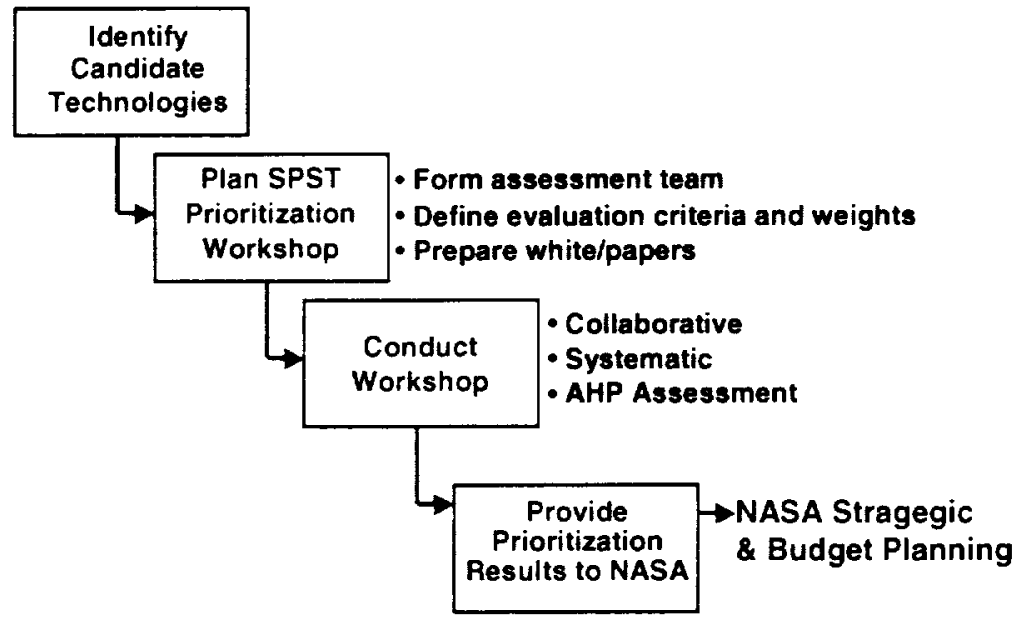

FIGURE 4

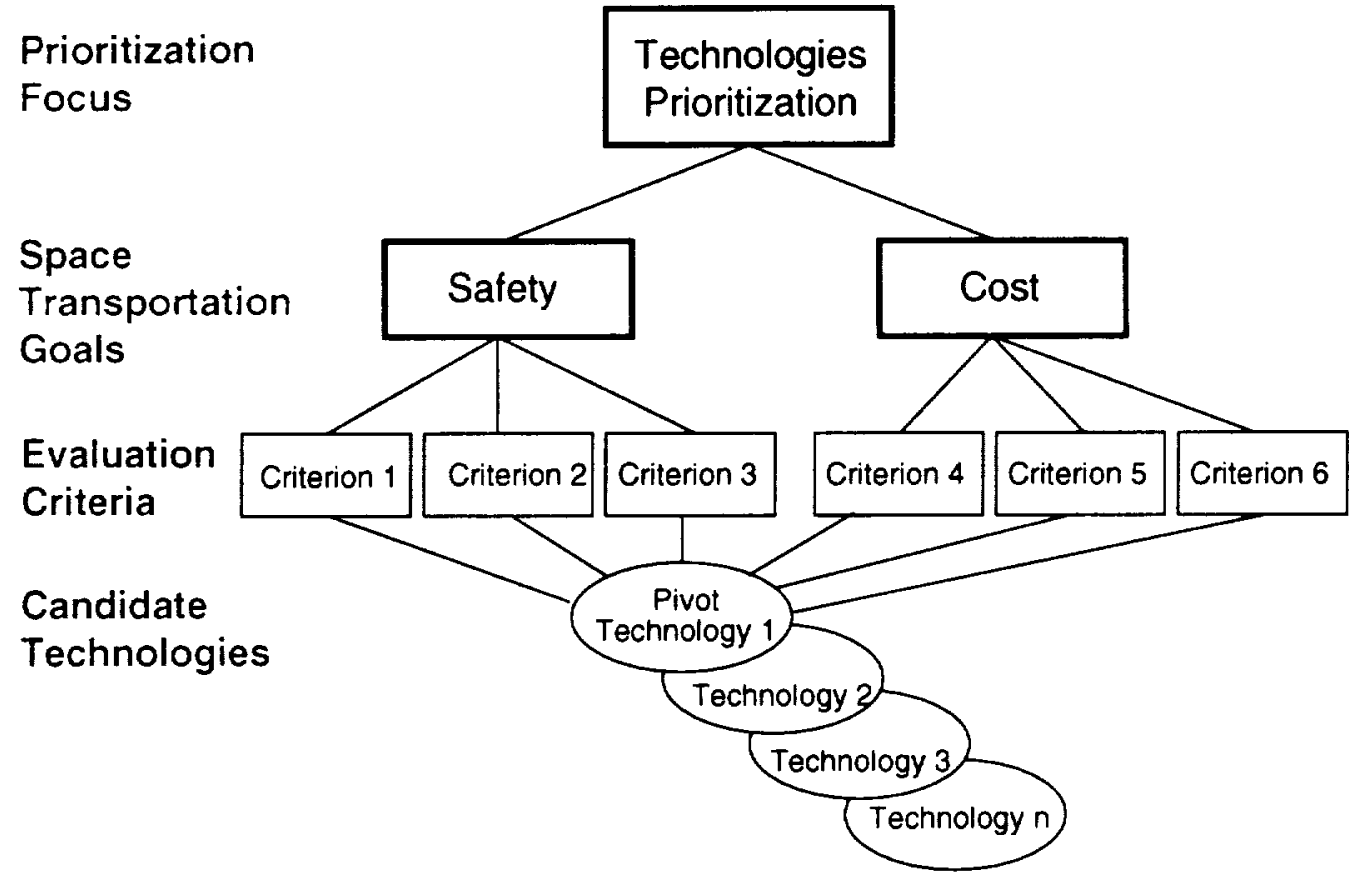

FIGURE 5 


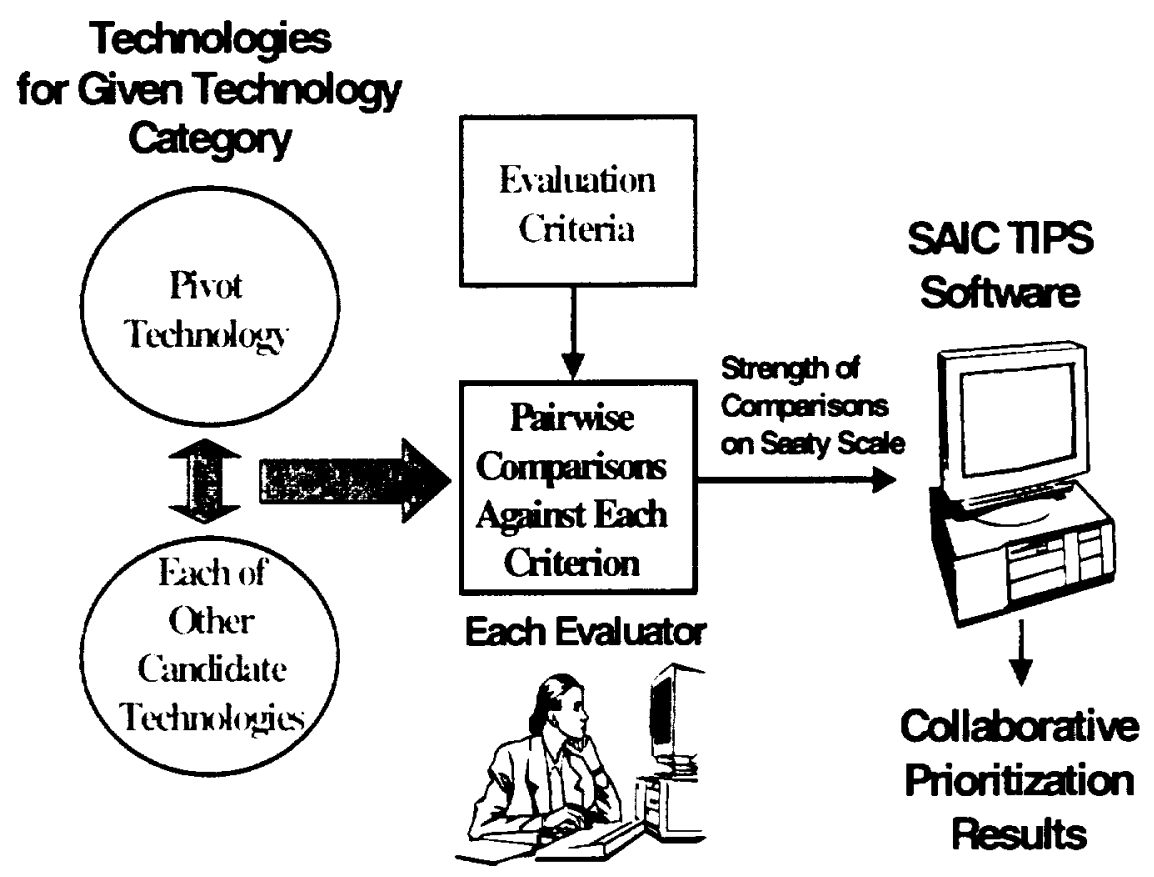

FIGURE 6

Priorities by Technology Category Across all Criteria Enabling/Generic Technologies

\section{Technology Priority}

Long life, light weight propulsion materials and structures $\quad 0.118$

Propulsion IVHM

0.116

Advanced cryotank structures

0.116

Combined OMS/RCS

0.115

NPSS for space transportation

0.103

Green propellant

0.093

Aerodynamic performance/control through drag modulation

0.085

High performance hydrocarbon fuels

0.078

Thrust augmentation

0.075

High density hydrogen

0.059

Bridge to Space

0.043

\section{FIGURE 7}


There are 11 enabling generic candidate technologies that were evaluated in the workshop. Therefore, the priority vector is an 11-component vector in which each candidate technology is represented by a number between zero and one, such that the 11 values sum to one. The higher the component number for a given technology, the higher is its relative priority.

With the preceding discussion in mind, one may interpret Figure 7 . The collaborative data indicate a cluster of four candidate technologies that surfaced as highest priorities in the enabling/generic category considering both technologies and programatic criteria: Long Life, Light Weight Propulsion Materials and Structures; Propulsion IVHM; Advanced Cryotank Structures; and Combined OMS/RCS. Their priorities are tightly grouped in the range between 11.5 and $11.8 \%$ of the 100 total points (i.e. priorities $0.118,0.116,0.116$ and 0.115 , respectively). Essentially these technologies were equally ranked.

Figure 8 and Figure 9 show the collaborative prioritization results for the 11 enabling/generic technologies based only on the weighted technical and the weighted programmatic evaluation criteria, respectively.

Figure 8 indicates a strong first priority $(0.133$ or $13.3 \%)$ for the Combined OMS/RCS technology based on the weighted technical criteria for Spaceliner class third generation RLV systems. However, as shown in Figure 9 the top two technology using the weighted programmatic criteria are Advanced Cryotank Structures and
Long Life, Light-Weight Propulsion materials and Structures.

The results of the assessment and prioritization of the candidate Flight Systems technologies are presented in the final report (Reference 7). They are again presented as assessed for the technical criteria and the programmatic criteria, as well as the results of the assessment using the combined criteria.

For example, the Long Life, High Thrust-to-Weight Hydrogen Rocket technology's high priority results from the fact that it is a very strong first priority technically, and is a strong third priority programmatically. The SSTO Hydrogen RBCC Propulsion technology's strong second priority derives from the fact of its solid third ranking technically, and its very strong first priority based on the programmatic evaluation criteria.

Other figures presented in Reference 7 document the summary baseline prioritization results for the four candidate Ground Systems technologies. It turned out that the workshop evaluators could not discriminate strongly among the given candidate technologies in terms of priorities. A slight preference for the Intelligent Instrumentation and Inspection Systems technology area is indicated.

The bottom line interpretation of the four Ground Systems technologies prioritization is that they are all needed for the Spaceliner program. 


\section{Priorities by Technology Category and Top Level Criterion Enabling/Generic Technologies}

\section{Technical}

Technology

Combined OMS/RCS

Propulsion IVHM

Green propellant

Long life, light weight propulsion materials and structures

NPSS for space transportation

Advanced cryotank structures

Aerodynamic performance/control through drag modulation

High performance hydrocarbon fuels

Bridge to Space

Thrust augmentation

High density hydrogen
Priority

0.133

0.114

0.111

0.100

0.097

0.096

0.088

0.084

0.061

0.061

0.055

\section{FIGURE 8}

\section{Priorities by Technology Category and Top Level Criterion \\ Enabling/Generic Technologies \\ Programmatic}

\section{Technology}

Advanced cryotank structures

Long life, light weight propulsion materials and structures

Propulsion IVHM

NPSS for space transportation

Combined OMS/RCS

Thrust augmentation

Aerodynamic performance/control through drag modulation

Green propellant

High performance hydrocarbon fuels

High density hydrogen

Bridge to Space
Priority

0.137

0.137

0.120

0.110

0.097

0.090

0.083

0.075

0.072

0.064

0.024

FIGURE 9 
Prioritization comes down basically to any development dependency sequencing, how much funding is required for each of these technologies, and the needed program timing of the development of each technology.

\section{Prospective Future SPST} Support Activities

There has been a general understanding that upon completion of the SL100 technology planning support (referred to as Phase I), contained in the final report for this effort (Reference 7), there would be a follow-on, Phase II activity requiring SPST support. There are several tasks under consideration, including the following:

1. Obtain more Management visibility out of technology assessment and prioritization results generated in the Phase I workshop. Using the technologies assessment data (technical and programmatic) presented in Chapter VII, it would be beneficial to develop quad charts that highlight the interrelation of these two criteria. This was done on previous studies by the SPST and can be very enlightening and beneficial to decision makers. For example, these quad charts can illustrate how an investment in technology can improve the programmatics such as risk, schedule, etc. (see Figure 10). Once this task is completed, the SPST intends to issue and addendum to this report. These quad charts can also provide visibility of time phasing of technology, e.g. Gen.2 or Gen.3. These quad charts can also provide visibility of time phasing of technology, e.g. Gen 2 or Gen 3.

HRST Architectural Assessment Preliminary Results

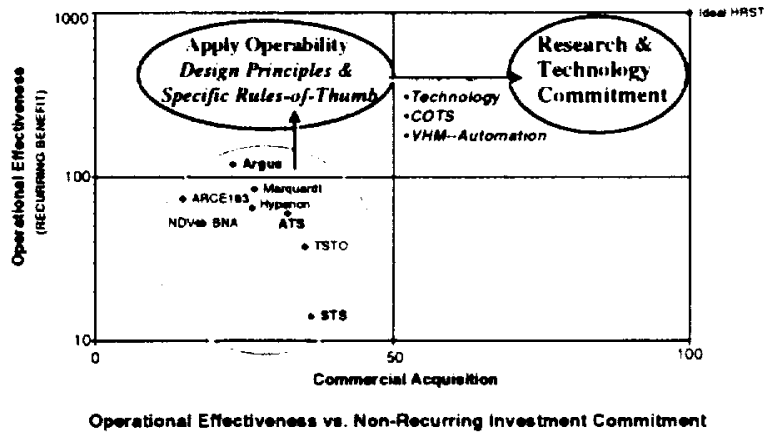

FIGURE 10

2. The SPST is in the process of developing an innovative approach, called "bottom up" to identifying and defining key enabling technologies for advanced transportation systems, both RLV/Gen 3 and RLV/Gen 2. In this approach, a select team from the SPST, with the proper experience and expertise, would first identify the specific impediments in our current space transportation system that prevents us from providing a space transportation system that has the desired characteristics referred to as "attributes". The work previously done by the SPST in identifying the design criteria that must be addressed to obtain a system with the required attributes will provide a base or starting point for identifying the "impediments" (see Reference 6). Once technologies have been identified by this process, they would be defined in 
technology white papers and assessed and prioritized in the same manner as that utilized in Phase 1 . It is anticipated that the "bottom up" approach will identify key enabling technologies that have been overlooked in the classic "top down" approach that has been utilized to date.

3. The SPST has been encouraged by Mr. Art Stephenson, MSFC Director, to study the analogy between the history of air transportation systems and the current space transportation system development. An exploratory task force has been formed, which is led by Bill Escher, SAIC and Dave Christensen, Lockheed Martin, to determine the approach and potential value of such a study.

4. In response to the MSFC Director, the SPST will be supporting the RLV/Gen 2 Program Management in determining and prioritizing technologies required to achieve the Gen 2 Goals. It is believed that the approach and process that the SPST has been using to support RLV/Gen3 technology planning will be directly applicable to the RLV/Gen 2 program.

5. Most of the above activities have been focused on space transportation services from earth to LEO. However, the task addressed herein did consider and recognized importance of interaction between an earth to LEO system and the transportation systems required to deliver payloads to other earth orbits, including GEO and beyond. Further, there are strong proponents, including Bob Sackheim, Assistant Director for Propulsion at MSFC, of the need to address space transportation as an integrated and optimized space transportation architecture. Therefore, we will be including this approach in considering follow-on plans for SPST support.

It should be noted that the SPST is in a unique position to support such an integrated approach to future space transportation planning. In addition to the recently completed support of SL100 technology planning for an earth to LEO RLV/Gen 3, the SPST has conducted other earth to LEO support activities, notably HRST and Access to Space. In addition, the SPST conducted one of the most comprehensive studies of $\mathrm{In}$ Space Transportation (propulsion technologies) that has been performed to date. Therefore, the SPST is well qualified to support a NASA task directed toward an integrated and optimized space transportation system and key enabling technology studies. In view of this, such a task is considered to be a strong candidate for the follow-on Phase II support of NASA/MSFC by the SPST.

6. In response to the MSFC SL-100 Gen 3 Program Manager, the SPST is continuing the development of an Algorithm for the "Systems Approach to Dependability, Responsiveness, Safety, and Affordability" 
supporting the Spaceliner 100 Functional Requirements. Operational effectiveness has been accomplished, but Programmatic factors must be added to complete the development followed by anchoring weights to actual database as best as possible.

\section{Concluding Remarks}

The Space Propulsion Synergy Team is a unique organization that has developed and successfully applied some new approaches and processes in addressing the challenge of future generations of space transportation systems. Actually, the SPST organization has been consistently supporting national level strategic planning for the development of a dependable, affordable space transportation service for almost a decade.

One reason for the longevity may be that the customers for SPST support (i.e., the national strategic planners and decision makers) recognize one very important fact; that major advancements in space propulsion systems and related technologies are the key to providing a space transportation service that meets the customer's needs at an affordable price. Thus, recognizing that propulsion systems have been the focus and the expertise of the SPST, the customers have continued to ask for and utilize the support of the organization.

Therefore, one should view the successful completion of the SPST support in defining and prioritizing
SL1000 candidate technologies reviewed in this paper as just one phase of a broader activity. There are proposals and plans to continue this support as outlined in the proceeding future plans section. These proposals include both support of RLV Gen 3 transportation systems (including SL 100 technologies) and the near term RLV Gen 2 systems.

Although there is and should be an emphasis on space propulsion technology advancement; it has been become exceedingly clear that future space transportation design must aggressively address all of the operational aspects. From the beginning, the design of transportation systems and sub systems must consider operational efficiency. This is obvious since the cost of operations is the major factor in the price of a space transportation service.

In the SPST approach/process used in the past and in the subject SL 100 technology support, the measurable design criteria focus on those criteria that will result in efficient operations. This approach not only reduces the operating cost but results in a more reliable and dependable transportation system. Only by following this approach in the design of all of the subsystems and components, etc., will we be able to attain the safety and affordability goals that are envisioned for the near term, RLV Gen 2 systems, let alone for the more challenging goals for a future RLV Gen 3 system.

The above considerations bring out another point. That is, the biggest benefit from the SPST support activities or SL 100 technologies and 


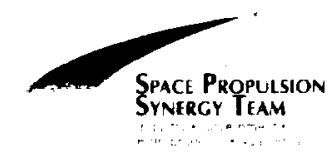

previous technology planning activities, may not be only in the results, i.e. prioritized technologies. Rather the development and employment of new approaches and processes that have evolved may result in a major cultural change in how we approach the design and operation of space transportation systems in the future.

\section{References}

1. AIAA 93-1851, "Overview of a Strategic Approach to Space Transportation" by Walter F. Dankhoff and William P. Hope, Jr., SRS Technologies, Arlington, VA. Presented at the AIAASSAE/ASME/ ASEE Joint (SPSG) Strategic Planning Support Efforts for Earth to Orbit Propulsion Conference and Exhibit, June 28-30, 1993, Monterey, CA.

2. AIAA 93-1852, "Payoffs For Applying QFD Technologies in the SPST Strategic Planning Support Effort for ETO Transportation and Propulsion Systems" by Jim Bray, Martin Marietta Manned Space Systems, New Orleans, LA. Publications, 4922 Ellsworth Avenue, Pittsburgh, PA 15213 1990.
Presented at the AIAASAE/ASME/ASEE Joint Propulsion Conference and Exhibit, June 28-30, 1993, Monterey, CA.

3. "Spaceliner 100 SPST Support" Prepared by Functional Requirements (Team 1)

Release Date - March 9, 2000

4. Reference to be used for SL100 Propulsion Technology Evaluation The Criteria Definition Reference Book Prepared by the Functional Requirements (Team 1)

Release Date - March 9, 2000

5. Saaty, Thomas L., "Decision Making for Leaders, The Analytic Hierarchy Process for Decisions in a Complex World", RWS

6. "A Guide for the Design of Highly Reusable Space Transportation", by the space Propulsion Synergy Team, August 29, 1997.

7. "Report of SPST Support of Spaceliner $100 \quad$ Technology Planning" by the SPST Technology Support Task Force - Sep '99 Apr '00 issued June 9, 2000. 


\section{APPENDIX A}

\section{Lessons Learned in the Conduct of the \\ Spaceliner 100 Technologies Prioritization Workshop}

The overall conduct and facilitation of the Spaceliner 100 Propulsion Technologies Prioritization Workshop was accomplished successfully. The planned technology prioritization products were produced on time to support the NASA budget planning process.

In the interest of continuing to improve the technologies assessment and prioritization process in support of NASA, the participants in the SPST Workshop were invited to submit their critique of the process and the workshop. The following paragraphs consolidate and summarize the inputs received from a number of the participants.

1. The consensus of all feedback received was that the workshop was extremely valuable and worthwhile, and provides a model for use in other programs within NASA. The AHP method was found to be a good way to systematically obtain balanced and reasoned inputs from many strong personalities in the expert evaluation team. The AHP provides great traceability to the why's of [the technology] rankings.

Lesson Learned: Continue to develop and use the overall SPST workshop approach and the Analytic Hierarchy Process to collaboratively assess and prioritize candidate technology investments to support the annual NASA budget planning process.

2. Many of the evaluators had difficulties accessing the candidate technology white papers, the workshop evaluation criteria definitions, Spaceliner 100 functional requirements, and other information on the MSFC server site. Getting a password allowing access to the site was unnecessarily difficult. Some evaluators requested but never received user IDs or passwords. Some white papers were not available on the site before the workshop. Hard copies of the white papers were not provided to the evaluators as backups before the workshop. These factors made it a real challenge for many of the evaluators to do their homework on the candidate technologies prior to coming to the workshop.

Lesson Learned: The white papers for all the candidate technologies, and all other workshop information, should be made readily available electronically ten days to two weeks prior to the workshop. Access to the server, where the papers are stored, should be made straightforward and simple to obtain for both PC and Macintosh users. Every evaluator should be encouraged to download and bring hard copies of the white papers, criteria definitions, and other information 
to the workshop for reference. A Help site should be set up to directly assist all participants.

3. It was observed that some of the candidate technology white papers did not specifically address the workshop evaluation criteria. Criteria were addressed that the advocate felt were important, but were not the evaluation criteria being addressed by the workshop. This caused a lot of questions and discussion that may have been unnecessary had the workshop criteria been addressed initially.

Lesson Learned. In future workshops, stronger emphasis should be placed on the white papers addressing the specific criteria to be used in the prioritization process. Although this is sometimes difficult to accomplish, it will serve to improve the efficiency with which the workshop can be conducted.

4. It was observed that some evaluators seemed to lack a full understanding of what the pivot technology was in certain instances, and why it was selected for assessing candidate technologies within a given technology category. Although some documentation and discussion was provided, there appeared to be a need for more formal briefings to refresh evaluator memories. There were not many metrics or benchmarks given to characterize pivot technologies, as a basis for making pairwise comparisons to the potential benefits offered by the candidate advanced technologies.

Lesson Learned. In future workshops, more time should be devoted to fully and formally review what each pivot technology is, and why it was selected as the pivot. Perhaps a summary sheet of information could be provided on each pivot to help facilitate the evaluators' pairwise comparisons to candidate advanced technologies.

5. With regard to the makeup of the technical and programmatic evaluator team, an oversight occurred in that no ground operations expert was included in the technical subteam. Two such evaluators worked together in the programmatic subteam. The ground operations perspective and experience are important to the technical as well as the programmatic evaluations of candidate technologies.

Lesson Learned. The mix of evaluators should be doublechecked to ensure that an operations knowledgeable expert is included in the technical subteam for future workshops.

All of the observations and comments from the participants were appreciated. The "Lessons Learned" provide a basis for continuing to improve the overall technologies prioritization process for the ongoing support of the NASA Advanced Space Transportation Program. 

政 